\title{
Influence of Microfibers Additive on the Self-healing Performance of Mass Concrete
}

\author{
Alaa Z. Dahesh ${ }^{\mathrm{a}^{*}}$, Farhad M. Othman ${ }^{()}{ }^{\mathrm{b}}$, Alaa A. Abdul-hamead \\ ${ }^{\text {a }}$ Department of Materials Engineering, University of Technology, Baghdad, Iraq. \\ mae.19.39@grad.uotechnology.edu.iq \\ ${ }^{\mathrm{b}}$ Department of Materials Engineering, University of Technology, Baghdad, Iraq. \\ 130031@uotechnology.ed.iq \\ ${ }^{\mathrm{c}}$ Department of Materials Engineering, University of Technology, Baghdad, Iraq. \\ 130043@uotechnology.ed.iq \\ *Corresponding author.
}

Submitted: 02/02/2020

Accepted: 27/03/2020

Published: 25/01/2021

\section{K E Y W O R D S}

Self- repair, Mass concrete, Polypropylene microfiber, Mechanical properties.

\section{A B S T R A C T}

Because cracks are the main problem of mass concrete, this paper investigates an experimental study on the effect of polypropylene microfiber (PPMFs) on self-repair behavior of mass concrete, through study the microstructure, workability, physical, and mechanical properties of mass concrete. PPMFs with a diameter of $18 \mu \mathrm{m}$ add in different percentages $(0,0.5,1$ and 1.5$) \%$ of cement weight. Where the prepared mixture ratio was (1:2:4.8) and the water-cement ratio $(W / C)$ was 0.4 . Also, $0.6 \%$ of Superplasticizer (SP) \% of cement weight to all concrete mixtures was added. In this study, an SEM analysis used to observe the effect of PPMFs on the microstructure of mass concrete, and compressive and flexural strength tests for study the mechanical properties of this. And referring to the analysis and discussion of the results, PPMFs used have changed the microstructure of mass concrete, and have an effective effect on improving compressive strength and flexural strength, and mechanism of sealing the cracks of concrete autogenously. Also, 1\% PPMFs (\% of cement weight) recorded as the highest addition, which has a positive effect on mass concrete properties to apply it in the construction field.

How to cite this article: A. Z. Dahash, F. M. Othman and A. A. Abdullah-hamead, "Influence of Microfibers on the Self-healing Performance of Mass Concrete" Engineering and Technology Journal, Vol. 39, Part A, No. 01, pp. 104-115, 2021.

DOI: https://doi.org/10.30684/etj.v39i1A.1581

This is an open access article under the CC BY 4.0 license http://creativecommons.org/licenses/by/4.0

\section{INTRODUCTION}

Cracks are the most common problem in mass concrete structures, such as concrete for dams, large piers, and foundations. Due to the low surface-to-volume ratio, most cracks are formed by the heat of cement hydration. Through the construction process, the temperature of the concrete will rise 
due to the exothermic reaction of the cement. This is especially a problem in mass concrete structures, which are most likely to thermal cracking at an early age due to the heat of hydration of cement. Because the surface of the structure radiates heat into the atmosphere, a thermal gradient occurs between the cold exterior of the structure or element and the warm core. Differences in free thermal expansion between parts of the structure will cause tensile stress on the surface [1-4]. If these stresses exceed the tensile strength of the concrete, cracking can occur. This is a common problem in engineering practice and may be exacerbated by adverse environmental conditions during the concrete pouring and curing process [3].

Numerous researches have been carried out on modifying the components of concrete, including change in cement matrix components by incorporation different types of fibers, like steel fiber, carbon fiber, polyethylene fiber, PVA fiber, and polypropylene fiber. Microfiber improves the structural integrity of the concrete, where previous research results showed the adding fibers to concrete mixtures results in a crack reduction, durability improvement, superior ductility, better energy absorption, and tensile strength enhancement. According to Pavel et al. [5], the addition of a small amount of carbon fiber improved the compressive and bending strength of concrete. In another study, H. Awang et al. [6] observed samples containing numerous fibers achieved higher compressive strength, tensile splitting strength, flexural strength, lower absorption and lower shrinkage readings than the control sample. Besides, the influence of fibers on cyclic freezing and thawing of concrete studied, when Berkowskia and Kazberuk [7] improved the scaling resistance significantly by using polypropylene and steel fibers. Also, evaluated the effect of different types of microfibers on the thermal properties of cementation materials was determined [8].

Many researchers studied the effect of different types of microfibers on tightening crack width, for example, Shunzhi et al. [9] studied the performance of self-repairing for ECC materials that included steel and wool fibers. Sun and Xu [10] used SEM analysis to investigate the microstructure of FRC where observed Polypropylene fibers acted as a network that bridge cracks after the first cracks occur, so preventing it from growing and supplying some warning time. Also, microfibers provide high bonding strength as shown by Mazloom and Mirzamohammadi [8] when studying the influence of the bond between microfibers and cement matrix on mechanical properties [11]. From the previous mention, most of these researches applied the microfibers in various cementation systems, but not applied in mass concrete class, as shown in this study. That investigated the effect of polypropylene microfibers on the restoration of the mechanical properties, and self-healing ability, after form micro-cracks in prism samples during flexural strength test, then observing a decrease in the crack width during the curing period.

The objective of this study is to fabrication a concrete mix suitable for mass concrete applications that have the ability for self-repair. where prepare number of concrete samples contain different rates of polypropylene microfibers, to observe the effect of these additives on the efficiency of selfhealing, through study the microstructure, physical, and mechanical properties of them.

\section{MATERIALS AND EXPERIMENTAL WORK}

This work consists of two routes, the first includes incorporating of microfiber PPMFs with concrete in three different percentages $(0.5,1$ and $1.5 \mathrm{wt} \%$ of cement weight), and then studying the influence of PPMFs on the performance of concrete. The second rout includes making micro-cracks in the concrete and studying the influence of PPMFs on the mechanism and period of the seal of these cracks.

\section{Materials and Prepared Samples Test}

\section{A. Materials}

As shown in Figure 1 PPMFs were supplied by Sika Fiber complied with ASTM C1116 [32]. Table I shows the typical properties of PPMFs at $25^{\circ} \mathrm{C}$. An aggregate of Najaf was used in the preparation of Mass concrete, crushed coarse aggregate with maximum particle size $40 \mathrm{~mm}$ (according to BS 5328-2:2009), and gradation of fine aggregate with the limits of zone1, Table II and III shown the properties of aggregate, and their grading that meets British standards BS 882:1992 [26], respectively. Sulfate-resistant cement (SRPC) is used in the preparation of mass concrete; Table IV summarizes the properties of SPRC. In all mixtures added $0.6 \%$ of cement weight by Superplasticizer as a chemical additive to reduce the water of mixing amount, which carry trade 
name Sika viscoCrete $-5930 \mathrm{~L}$, which has form as a viscous liquid and with basis as an aqueous solution of modified polycarboxylate and has an appearance like turbid liquid with density $1.1 \mathrm{~g} / \mathrm{cm}^{3}$, which is identical to the British specification EN 934-2:2001 [33]. Potable water that has $\mathrm{PH}=7.5$ used for mixing and curing all samples in this study.

TABLE I: Typical Properties of PPMFs at $25^{\circ} \mathrm{C}$.

\begin{tabular}{cc}
\hline \hline Property & Value \\
\hline Component & Single \\
\hline Form & Fibrous \\
\hline Color & White \\
\hline Specific gravity & $0.92+/-0.02$ \\
\hline Standard length & $3,6,12$ and $18 \mathrm{~mm}$ \\
\hline Tensile strength & $350 \mathrm{~N} / \mathrm{mm}^{2}$ \\
\hline Modulus of Elasticity & $5000 \mathrm{~N} / \mathrm{mm}^{2}$ \\
\hline Elongation at break & $25 \%$ \\
\hline Softening point & $140{ }^{\circ} \mathrm{C}$ \\
\hline Melting point & $160{ }^{\circ} \mathrm{C}$ \\
\hline Alkali Resistance & Excellent \\
\hline
\end{tabular}

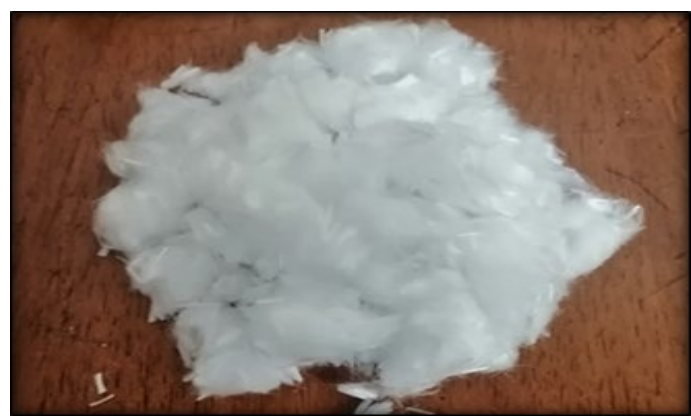

Figure 1:PPMFs.

TABLE II: The properties of Fine and Coarse Aggregate chemically and physically.

\begin{tabular}{cccc}
\hline \hline Properties & Fine agg. & Coarse agg. & $\begin{array}{c}\text { B.S limits EN } \\
\mathbf{1 2 6 2 0 : 2 0 1 3}[\mathbf{3 4}]\end{array}$ \\
\hline Specific gravity & 2.63 & 2.5 & $2.4-2.8$ \\
\hline Dry compacted density $\left(\mathbf{m g} / \mathbf{m}^{3}\right)$ & 1.6 & 1.78 & $1.12-1.78$ \\
\hline Water Absorption $\%^{\text {S }} \boldsymbol{O}_{\mathbf{3}} \%$ & 0.86 & 1 & - \\
\hline Fineness modulus & 0.038 & 0.08 & $\leq 0.2$ \\
\hline
\end{tabular}

TABLE III: $\quad$ Grading of Fine and Coarse Aggregate and Requirements.

\begin{tabular}{cccccc}
\hline \hline B.S. sieve & $\begin{array}{c}\text { percentage by weight } \\
\text { passing } \\
\text { Fine agg. }\end{array}$ & B.S. sieve & \multicolumn{2}{c}{$\begin{array}{c}\text { percentage by weight } \\
\text { passing } \\
\text { Coarse agg. }\end{array}$} \\
\hline (in) & $(\mathrm{mm})$ & Grading zone 1 & (in) & (mm) & $11 / 2-3 / 16$ (in), 38-5 (mm) \\
\hline $3 / 8$. & 9.52 & 100 & 3 & 76.2 & 100 \\
\hline $3 / 16$. & 4.76 & $90 / 100$ & $21 / 2$ & 63.5 & - \\
\hline NO.7 & 2.4 & $60 / 95$ & $11 / 2$ & 38.1 & $95 / 100$ \\
\hline NO.14 & 1.2 & $30 / 70$ & $3 / 4$ & 19.05 & $30 / 70$ \\
\hline NO.25 & 0.6 & $15 / 34$ & $1 / 2$ & 12.7 & - \\
\hline NO.52 & 0.3 & $5 / 20$ & $3 / 8$ & 9.52 & $10 / 5$ \\
\hline NO.100 & 0.15 & $0 / 10$. & $3 / 16$. & 4.76 & $0 / 5$ \\
\hline
\end{tabular}

TABLE IV:Chemical Composition and Main Compounds of SRPC. 


\begin{tabular}{|c|c|c|c|c|c|c|c|c|c|c|c|c|}
\hline $\begin{array}{c}\text { Oxides } \\
\text { Composition }\end{array}$ & $\begin{array}{c}\mathrm{Ca} \\
\mathrm{O}\end{array}$ & $\mathrm{SiO}_{2}$ & $\mathrm{Al}_{2} \mathrm{O}_{3}$ & $\mathrm{Fe}_{2} \mathrm{O}_{3}$ & MgO & $\mathrm{SO}_{3}$ & L.O.I. & $\begin{array}{l}\text { Insoluble } \\
\text { residue }\end{array}$ & L.S.F & $\mathrm{C}_{3} \mathrm{~S}$ & $\mathrm{C}_{2} \mathrm{~S}$ & $\mathbf{C}_{3} \mathbf{A}$ \\
\hline Content \% & 60.69 & 20.4 & 5.7 & 3.12 & 2.86 & 1.8 & 3.23 & 1.09 & 0.77 & 41.7 & 27.5 & 10 \\
\hline $\begin{array}{l}\text { Limits of B.S } \\
4027[27]\end{array}$ & - & - & - & - & $<5$ & $<2.5$ & $<4$ & $<1.5$ & - & - & - & - \\
\hline
\end{tabular}

B. Mix Proportion

The mixing proportion was according to British standards B.S 5328-2-1997 [25]. Table V includes details of the mixing ratios of $1 \mathrm{~m}^{3}$ concrete grades $\mathrm{C} 20$.

TABLE V: Proportions of Mix in $\mathrm{Kg} / \mathrm{m}^{3}$.

\begin{tabular}{cccccccc}
\hline \hline Type & $\begin{array}{c}\text { PPMFs } \\
\left(\mathbf{K g} / \mathbf{m}^{\mathbf{3}}\right)\end{array}$ & $\begin{array}{c}\text { Cement } \\
\left(\mathbf{K g} / \mathbf{m}^{\mathbf{3}}\right)\end{array}$ & $\begin{array}{c}\text { Fine agg. } \\
\left(\mathbf{K g} / \mathbf{m}^{\mathbf{3}}\right)\end{array}$ & $\begin{array}{c}\text { Coarse agg. } \\
\left(\mathbf{K g} / \mathbf{m}^{\mathbf{3}}\right)\end{array}$ & $\begin{array}{c}\text { Water } \\
\left(\mathbf{K g} / \mathbf{m}^{\mathbf{3}}\right)\end{array}$ & $\begin{array}{c}\text { SP } \\
\left(\mathbf{K g} / \mathbf{m}^{\mathbf{3}}\right)\end{array}$ \\
\hline 1 & Control & 0 & 280 & 576 & 1344 & 112 & 1.68 \\
\hline 2 & $0.5 \%$ PPMFs & 1.4 & 278.6 & 576 & 1344 & 112 & 1.68 \\
\hline 3 & $1 \%$ PPMFs & 2.8 & 277.2 & 576 & 1344 & 112 & 1.68 \\
\hline 4 & $1.5 \%$ PPMFs & 4.2 & 275.8 & 576 & 1344 & 112 & 1.68 \\
\hline
\end{tabular}

Mix ratio 1:2:4.8

\section{Preparation of Mixes and Casting}

After weight raw materials for concrete components which it is details shown in Table 5, fine aggregate, cement, and coarse aggregate dry-mixed by concrete mixer for three minutes then added SP and water which add with it PPMFs for dry mixture, and mixed for two minutes, After that, was oiled the inner sides of the molds with a thin oil layer, to take the specimens of concrete out easily at later, Then, concrete mixture poured in the prism molds with dimensions of $(75 * 75 * 300) \mathrm{mm}$ according to BS 12390-5-2009 [31] for flexural strength test, and in cube molds with dimensions of $(150 * 150 * 150) \mathrm{mm}$ according to BS 1881-116 [29] for the compressive strength test.

The mixing process was done at normal conditions where the ambient temperature was $27^{\circ} \mathrm{C}$, and the treatment process was in moist condition by immersion the hardened specimens after removal from molds in water tank according to BS standard 1881-Part 111[35].

\section{II.Tests}

\section{A. Fresh Concrete Workability}

To detect the effect of PPMFs on the workability of concrete, the same amount of W/C and SP was applied to all concrete mixtures, and through slump testing, this effect can be inferred, as in this test a cone can be used with dimensions of $(300 \times 100 \times 200) \mathrm{mm}$ (height of the cone, a diameter of top and base cone) respectively, according to BS1881-102 1983 [28].

\section{B. Physical Properties}

Dry density, Porosity, and water absorption can be determined according to ASTM (C642-97) [30]. Parts from crushed concrete samples in the compressive strength test are used in this test. Firstly, when samples are received take the first weight for its, then the samples were immersed in water for one day. After that, weighed samples again after it takes off from water and recorded as second weight. Finally, determines the third weight of the samples submerged in water, the results of these tests can be calculated from the following equations:

$$
\begin{gathered}
\text { Dry density }\left(\mathrm{g} / \mathrm{cm}^{3}\right)=\left[w_{1} /\left(w_{2}-w_{3}\right)\right] * \rho_{w} \\
\text { Absorption of Water }=\left[\left(w_{2}-w_{1}\right) / w_{1}\right] * 100 \% \\
\text { Porosity }=\left[\left(w_{2}-w_{1}\right) /\left(w_{2}-w_{3}\right)\right] * 100 \%
\end{gathered}
$$

Where, $\mathrm{W}_{1}$ : Weight of dry sample $(\mathrm{g}) ; \mathrm{W}_{2}$ : Weight of wet sample $(\mathrm{g}) ; \mathrm{W}_{3}$ : Weight of the submerged sample in water $(\mathrm{g}) ; \rho_{\mathrm{w}}$ : Density of water, which is equal to $1\left(\mathrm{~g} / \mathrm{cm}^{3}\right)$. 


\section{Compressive Strength Test}

A compressive strength test was done according to B.S.1881-116 [29], in this test use a compressive strength test machine (TONI PACT 3000/Germany). The loading rate was about 0.25 $\mathrm{MPa}$ per sec. The average result of three prepared concrete specimens with dimensions $(150 \times 150 \times 150) \mathrm{mm}$ was reported for each mixture, and this test applied on 7 - and 28-days age, using the following equation for determining compressive strength.

$$
\sigma=\mathrm{P} / \mathrm{A}
$$

Where, $\sigma$ : Compressive strength, MPa; P: Ultimate compressive load, N; A: Sample area, $\mathrm{mm}^{2}$

\section{Flexural Strength Recovery Test}

Three-point bending is examined according to BS EN 12390-5: 2009 standards [31], before the test, a notch is made to a depth of $3 \mathrm{~mm}$ below each prism at mid-base by using a diamond circularly saw, notch act as stress concentration points for control spreading cracks at the tip of it. The download speed was $0.04 \mathrm{~mm} / \mathrm{min}$. The mean results of three prepared concrete samples were recorded with dimensions $(75 \times 75 \times 300 \mathrm{~mm})$ at 7 days of age. and when complete the test, samples were re-immersed in the water tank vertically to keep the surface of the crack in contact and leave for further 28 days [6], the bending strength can be determined for (1st R) and (2nd R) from Eq. (5):

$$
F_{c t}=\frac{F * I}{d_{1} * d_{2}^{2}}
$$

Where, $\mathrm{F}_{\mathrm{ct}}$ : is the flexural strength, in $\mathrm{MPa}\left(\mathrm{N} / \mathrm{mm}^{2}\right)$; $\mathrm{F}$ : is the maximum load, in $\mathrm{N}$; $I$ : is the distance between the supporting rollers, in $\mathrm{mm} ; \mathrm{d}_{1}$ and $\mathrm{d}_{2}$ : are the lateral dimensions of the specimen, in $\mathrm{mm}$.

To evaluate flexural strength recovery, the same prism samples are tested from both mixtures again after healed for 28 days from initiate the first cracks (2nd R), and through applicant Eq. (6):

$$
\text { Efficiency of healing } \eta \%=f_{c t 1} / f_{c t 2}
$$

Where, $\eta \%$ : is efficiency of healing; $f_{c t 1}$ : is maximum stress of original sample $(1 \mathrm{st} R) ; f_{\mathrm{ct} 2}$ is maximum stress of healing sample ( $2 \mathrm{nd} \mathrm{R}$ ); crack detection microscope was used to analyze the crack seal at various times. Every week removed samples from the water to measure the width of the crack, and to take photography to estimate \% strength recovery over time. The cracked prisms were marked where readings were determined.

\section{RESUlTS AND DisCUSSION}

\section{Slump Test Results}

The slump test results for all mixtures in Figure 2 shows that they are related to the content of PPMFs. The test value decreases significantly as the content of PPMFs in the mixture increases, slump value for $1.5 \%$ PPMFs sample reached $74 \mathrm{~mm}$, while the slump value of mass concrete (max size aggregate $40 \mathrm{~mm}$ ) is $75 \mathrm{~mm}$ according to BS 5328-2-1992. The decline of mobility occurs principally due to PPMFs preventing the relative movement of mixture particles, this result corresponds with previous research [12]. 


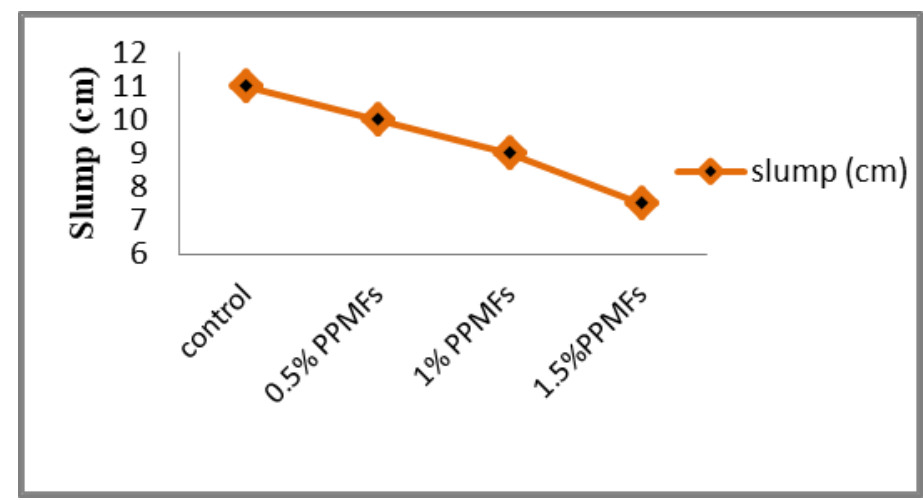

Figure 2: Slump Test Results for all Fresh Concrete Mixtures Samples.

\section{Mechanical Test Results}

Figure 3 shows the compressive strength test results at ages 7 and 28 for all cube samples and the results of the test in Figure 3 represent as average for every three samples. wherein the results of early age ( 7 days age), the all-added mixtures showed an increase in compressive strength when compared with a reference sample, all mixtures (reference and all PPMFs mixtures) excessed the target strength of $20 \mathrm{MPa}$ at the age of 28 days, Development of compressive strength of all samples may return to the effect of high-performance Superplasticizer (Sika ViscoCrete 59301) which represent as a parameter that lower water-cement ratio that required in concrete mixture preparation, also this phenomenon is likely to occur because of the type of cement (SRPC) used in the mixture which has less $\mathrm{C} 3 \mathrm{~S}$ content, linked with development in strength at an early age and high $\mathrm{C} 2 \mathrm{~S}$ content associated with long-term age strength development.

Moreover, the mixture which has 1\% PPMFs exhibited significantly the highest compressive strength at both ages 7 and 28 days, respectively, however, but when exceeding \%MF over $1 \%$ the reduction in strength occurs at all curing ages, The same effect occurs with the flexural strength test, where according to results of compressive strength, prism with $1 \%$ PPMFs were chosen to compare with reference samples to predict flexural strength results, the prism with $1 \%$ PPMFs reached to the highest result 14.6 MPa at age 7days, while the reference sample did not exceed $13.54 \mathrm{MPa}$ at same age [12-14].

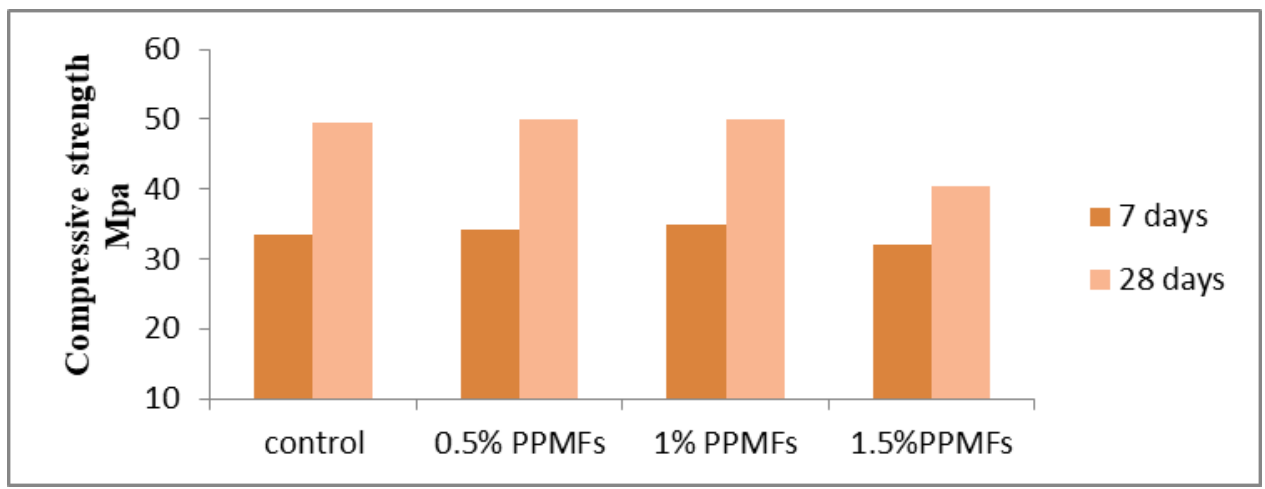

Figure 3: Results of Compressive Strength Test for all Samples.

To assess the flexural strength recovery, prism specimens from the two mixtures which cracked after 7 days of water curing (1st R) return to further curing for 28 days, then test again ( $2 \mathrm{nd} R$ ), Figure 4, and According to Eq. (6), this could illustrate that the PPMFs and reference specimen recovered $91.1 \%$ and $72.38 \%$ of their original flexural strength (1st R) respectively, Figure 5, this is an indication of the efficacy of using PPMFs as a healing agent when compared with the control specimen [9]. 


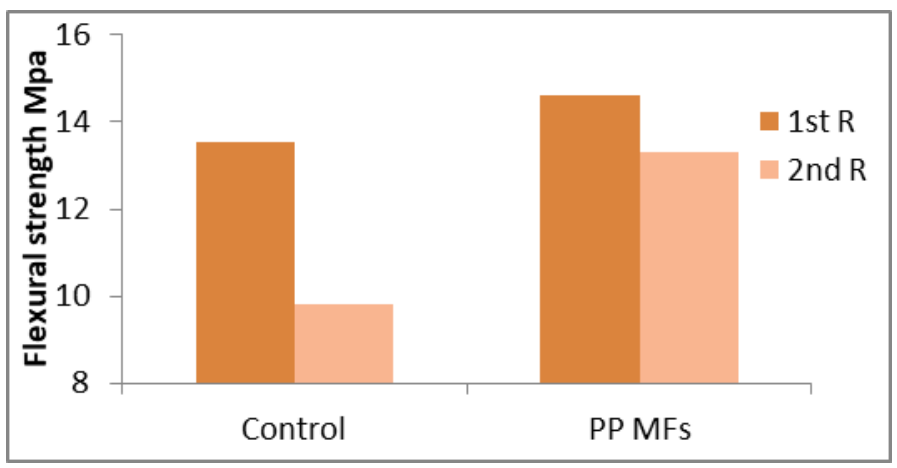

Figure 4: Curve of Flexural Strength Values at $1^{\text {st }}$ and $2^{\text {nd }} R$.

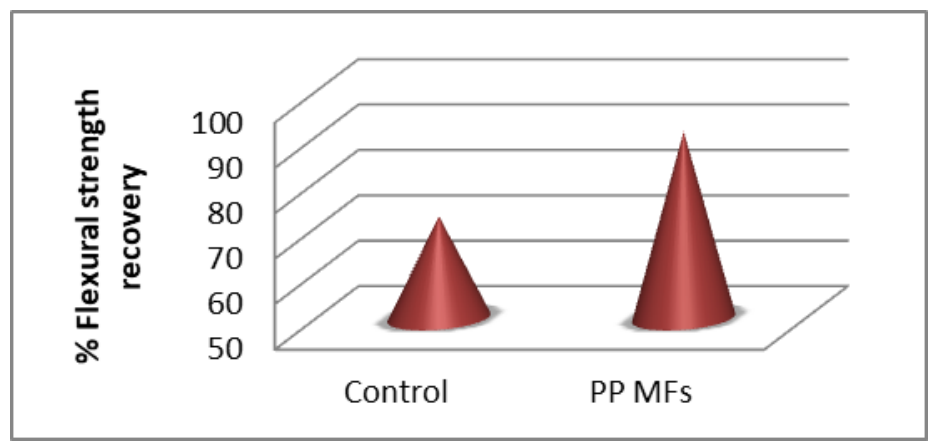

Figure 5: Percentage of Flexural Strength Recovery of Samples with and without PPMFs.

\section{Evaluation of the seal of crack by microscopy}

After forming the cracks in all samples at 7 days age, and after 28 days of healing in water, since fabricating initial cracks, observed cracks by microscope. Where the percentage of healing values after 28 days for the control sample and PPMFs sample are shown in Figure 7, also Figure 8 shows the shape of the cracks observed by the microscope, and the best reduction in crack width was at a PPMFs specimen, as shown in Figure 6, where PPMFs act as bridges, allow to un hydrated Cementitious Material to initiate continuous reaction during the period of self-healing and tighten cracks width $[2,9]$.

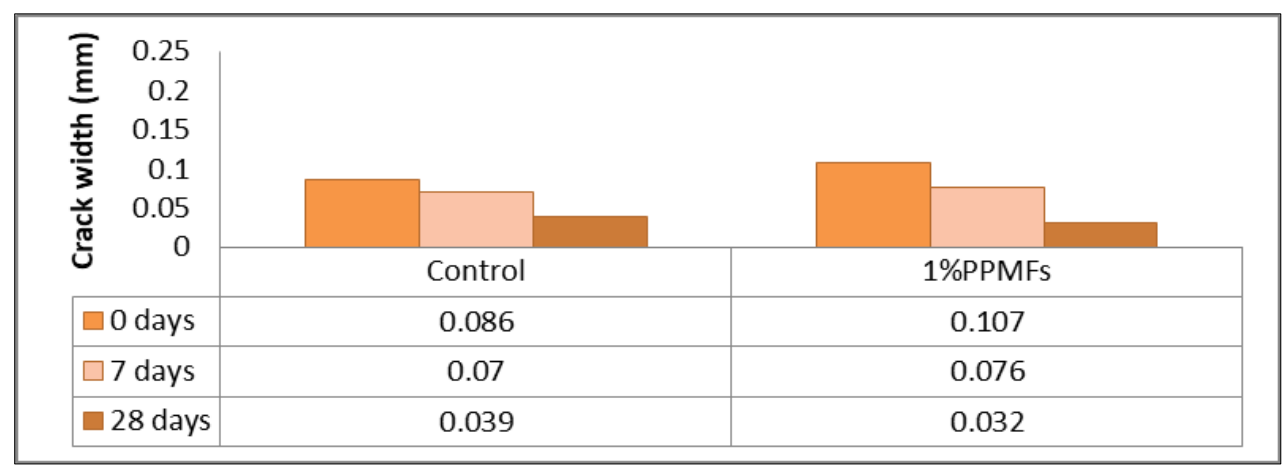

Figure 6: Reduction of Crack width with the Time of Healing for prism Samples. 


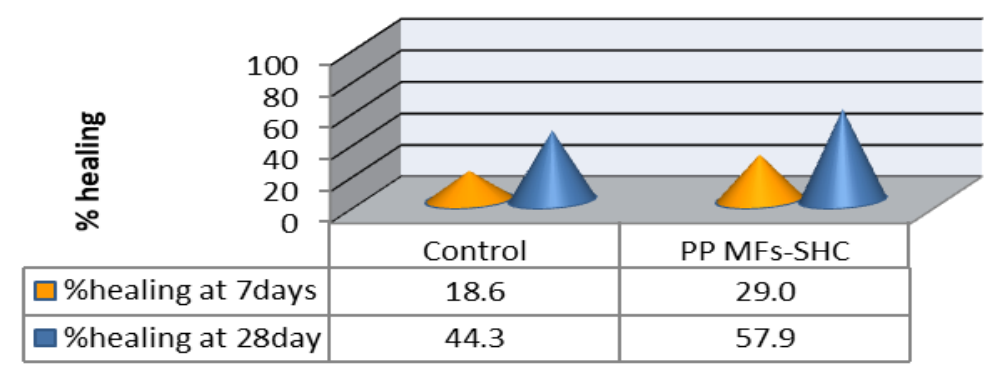

Figure 7: Percentage of Sealing of Cracks for prism Samples after 7, 28 day of Healing Period.

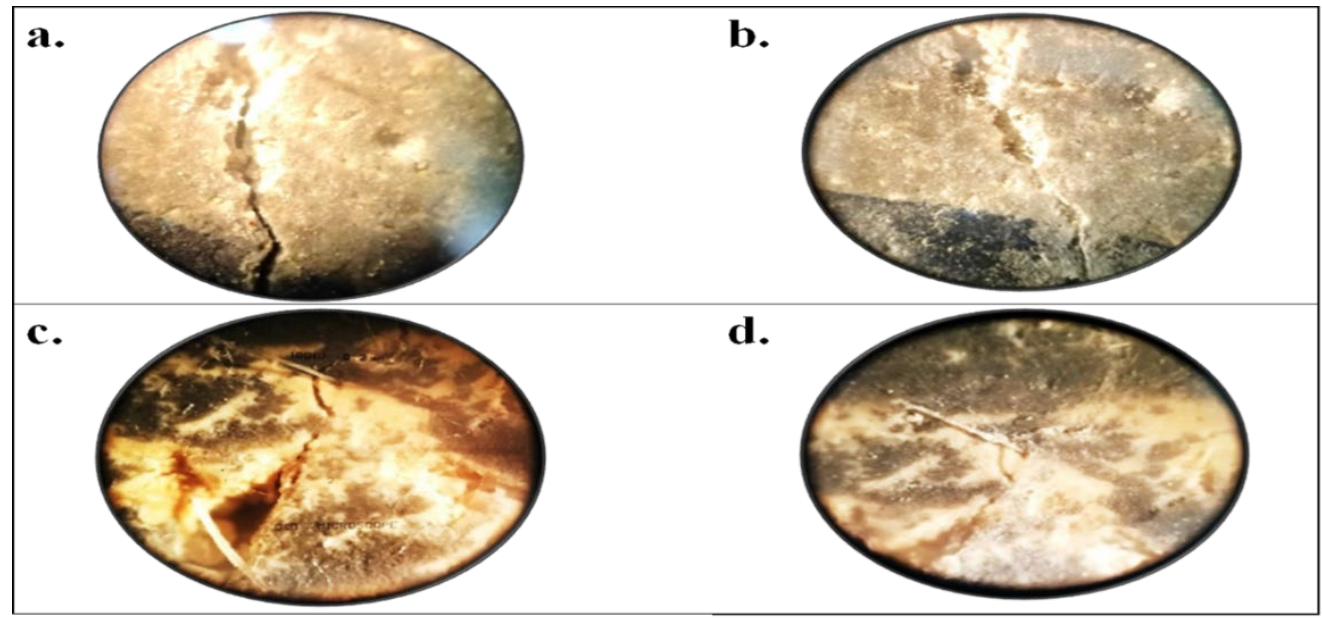

Figure 8: Cracks before healing (left) and after healing (right) (a and b: control specimen) (c and d: PPMFs specimen).

\section{|IV. Physical Properties Results}

According to experimental methods for examining the physical properties of all concrete mixtures, the dry density increases with an increase of \% PPMFs at 7- and 28-days age as shown in Figure 9 [10,15], porosity and water absorption results provided decrease with an increase of $\%$ PPMFs [10] Figure 10 and 11.

Results indicate that PPMFs significantly densest the microstructure of concrete, and largely reduces voids causing in reduce absorption, led to enhance mass concrete properties as observed in mechanical tests in this study.

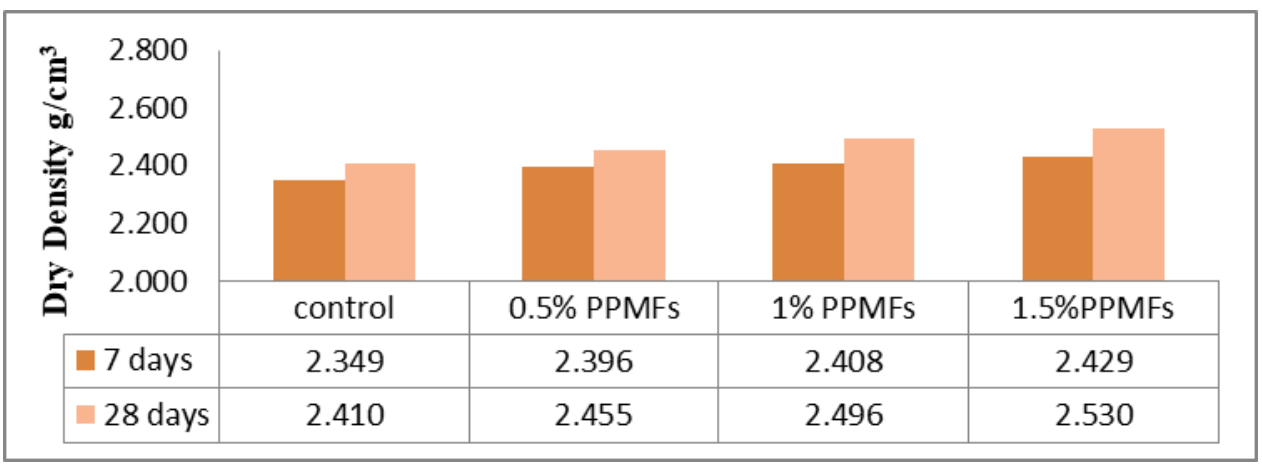

Figure 9 :Dry Density of all Concrete Samples. 


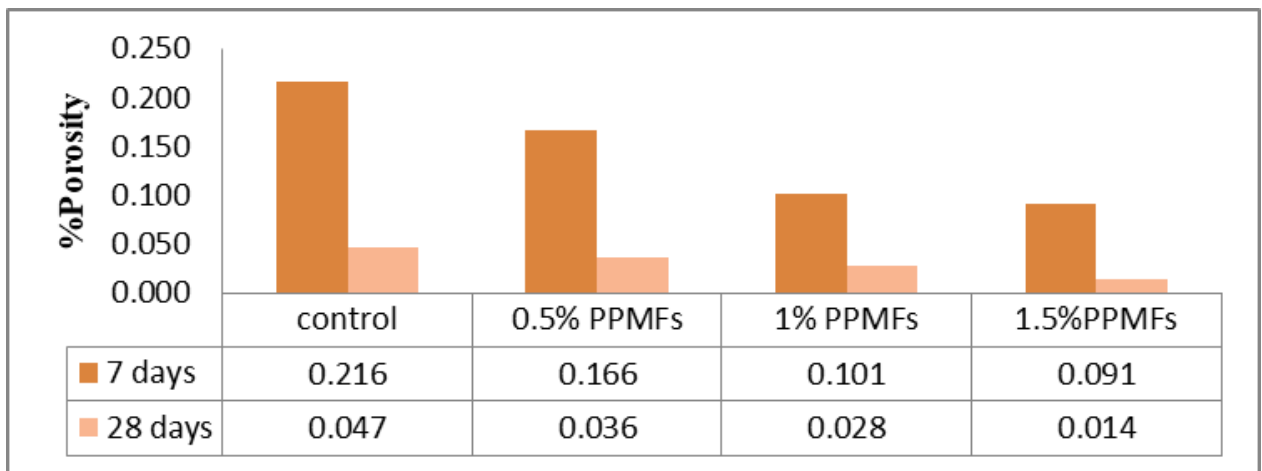

Figure 10: Percentage of Porosity for all Samples.

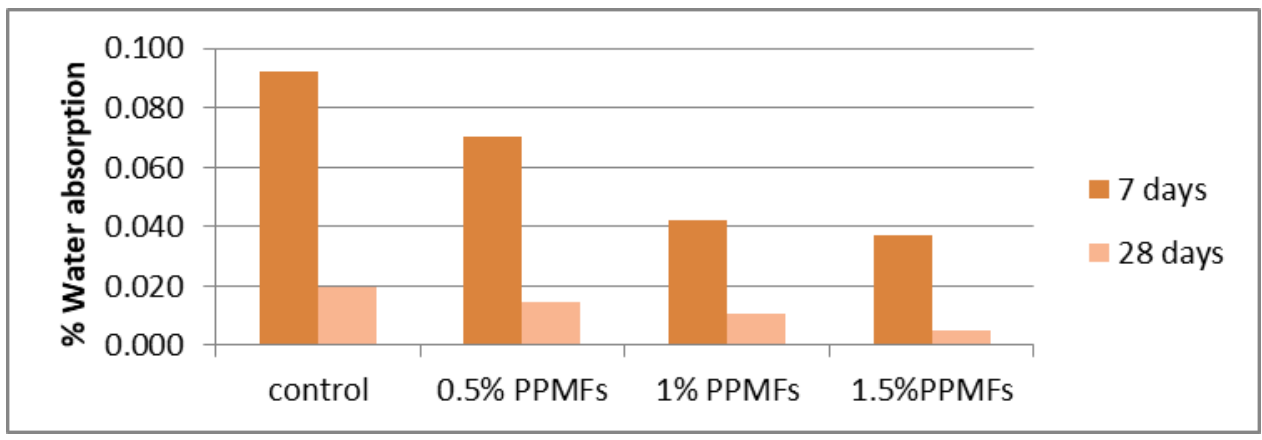

Figure 11: Percentage of water absorption of all samples.

\section{SEM Results of Concrete with and without PP MFs}

Figures 12 and 13 display SEM images of the control sample, and mixed sample $(0.5,1,1.5) \%$ PPMFs, after compression strength testing of cube samples at the ages of 7 and 28 days, cracked samples return to the water tank to further 28 days, and using SEM to analyze crack area. Results shown PPMFs change mass concrete microstructure, the grain size increases, and CSH gel expands as healing compounds until it fills almost all voids, due to the effect of the bridge, which is produced by PPMFs, that enhance heal the cracks autogenously. While in Figure 12 concrete without PPMFs, a gel was observed but containing porosity because the reaction is incomplete.

Also, in Figure 13 (b), optical testing of the microstructure of the sample containing $0.5 \%$ of PPMFs showed the appearance of nanoparticles compared to the usual concrete model, that's because PPMFs form a network that restricts the growth of calcium hydroxide, causing dense microstructure and shrinking fine voids by further expanding the CSH gel $[9,10]$.

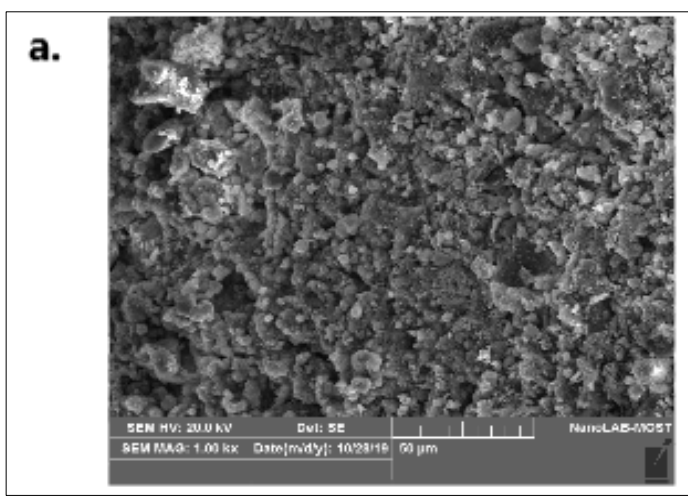

b.

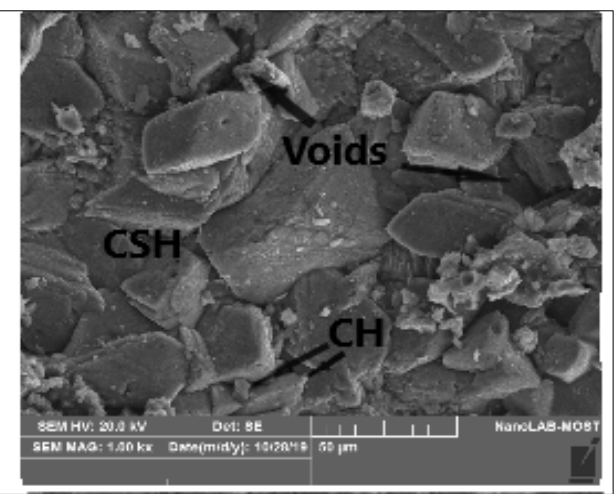

Figure 12: SEM for Control Sample after heals during 28 days(7 days age on left)

(28 days age on right). 


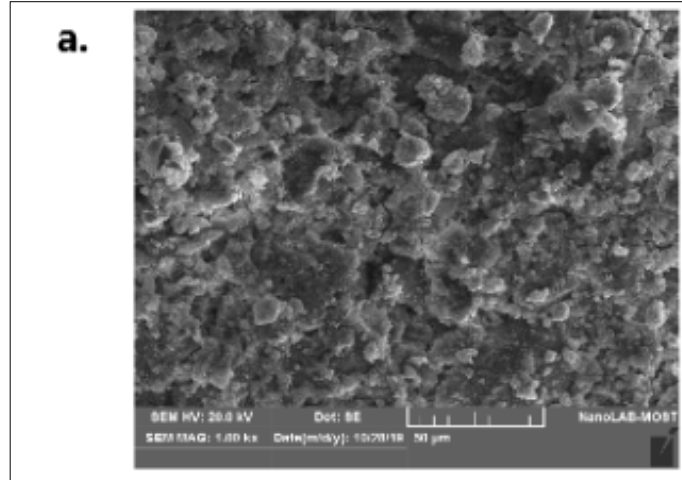

c.

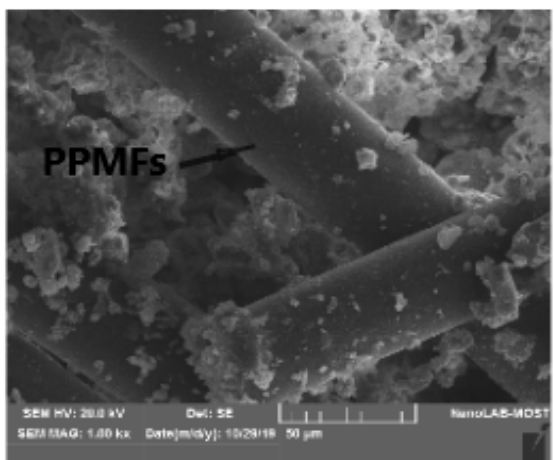

e.

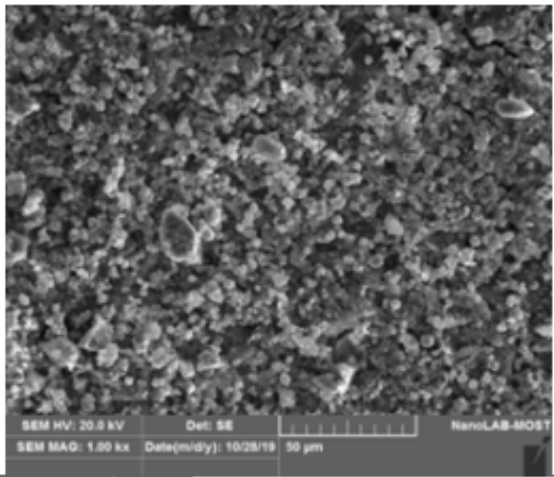

b.

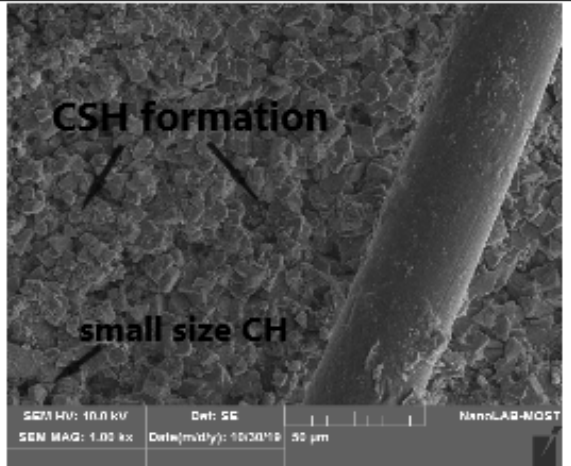

d.

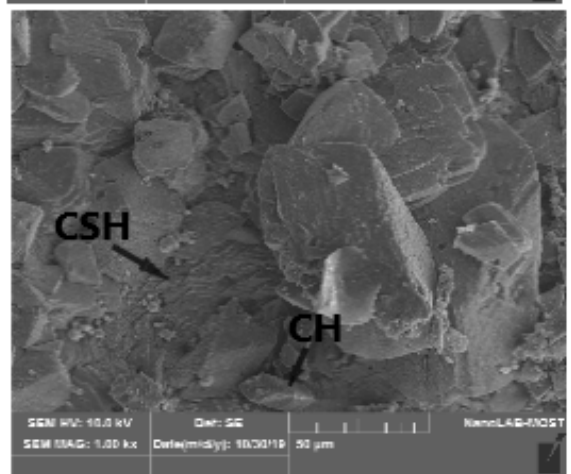

f.

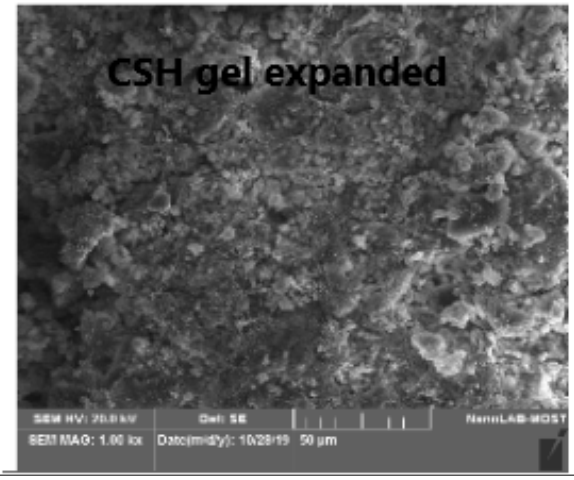

Figure 13 : SEM for Mixed Samples after heals during 28 days: (7 days age on left)

(28 days age on right) (a, b 0.5\% PPMFs), (c, d 1\% PPMFs) and (e, f 1.5\% PPMFs).

\section{CONCLuSion}

Experimental results suggest PPMFs significantly reduced workability with \%PPMFs increased. The inclusion of PPMFs in mass concrete leads to an increase in its compressive strength and flexural strength recovery. However, the required compressive strength greater than $20 \mathrm{MPa}$ can be achieved for contents less than 2\%PPMFs. It also improves the physical properties of the mass concrete. PPMFs with $1 \%$ significantly improves the sealing of cracks of mass concrete by up to (29-57) $\%$ at 7 and 28 days age of the healing period, respectively, which is better than control samples that achieved (18.6-44.3) \% at 7and 28 days age of the healing period, respectively. The presence of PPMFs leads to the intensification microstructure of concrete. It acts as a network that limits the size, content, and direction of $\mathrm{CH}$ crystals and micro-voids. A $1 \%$ PPMFs was considered an environmental and sustainable choice for building applications.

\section{References}

[1] T. Du Do, T. Lam, Solutions to improve the quality of mass concrete construction in climate conditions of Southern Vietnam, Int.J. Innov. Technol. Explor. Eng., 8 (2019)188-192. 
[2] D. Shen, X. Liu, Q. Li, L. Sun , W. Wang, Early-age behavior and cracking resistance of high-strength concrete reinforced with Dramix 3D steel fiber, Constr. Build. Mater., 196 (2018) 307-316. https://doi.org/10.1016/j.conbuildmat.2018.10.125

[3] S. Doshi, D. Patel, Kevina B. Patel, Kajal B. Patel, P. Mavani, Methodology for prevention and repair of cracks in building, GRD J. Eng., 3(2018)52-57.

[4] N. Shi, Y. Chen , Z. Li, Crack risk evaluation of early age concrete based on the distributed optical fiber temperature sensing, Adv. Mater. Sci. Eng., 2016 (2016) 1-12. https://doi.org/10.1155/2016/4082926

[5] P. Tesarek, P. Holub, J. Havrda, J. Fladr, Z. Prosek, J. Trejbal, T. Placgy, Mechanical properties of cement composites reinforced by carbon microfibers: compressive and bending strength, Key Eng. Mater., 722 (2016) 351-356. https://doi.org/10.4028/www.scientific.net/KEM.722.351

[6] H. Awang, M. H. Ahmad, M. Z. Al-Mulali, Influence of kenaf and polypropylene fibers on mechanical and durability properties of fiber reinforced lightweight foamed concrete, J. Eng. Sci. Technol., 10 (2015) 496 508 .

[7] P. Berkowskia, M. Kazberuk, Effect of fiber on the concrete resistance to surface scaling due to cyclic freezing and thawing, Procedia Eng., 111 (2015) 121-127. https://doi.org/10.1016/j.proeng.2015.07.065

[8] M. Mazloom ,S. Mirzamohammadi, Thermal effects on the mechanical properties of cement mortars reinforced with aramid, glass, basalt and polypropylene fibers, Adv. Mat. Res., 8(2019) 137-154. http://dx.doi.org/10.12989/amr.2019.8.2.137

[9] S. Qian, Z. Zhang, E. Tziviloglou, S. Antonopoulou, J. Zhou, E. Schlangen, Influence of microfiber additive effect on the self-healing behavior of engineered cementitious composites, The Second International Conference on Sustainable Construction Materials: Design, Performance, and Application, China, 2012. https://doi.org/10.1061/9780784412671.0018

[10] Z. Sun, Q. Xu, Microscopic, physical and mechanical analysis of polypropylene fiber reinforced concrete, Mater. Sci. Eng. A, 527(2009)198-204. https://doi.org/10.1016/j.msea.2009.07.056

[11] C. Del Prete, N Buratti, S Manzi, C. Mazzotti, Macro synthetic fiber reinforced concrete: Influence of the matrix mix design on interfacial bond behavior, IOP Conf. Ser.: Mater. Sci. Eng., 596, 2019,012025. https://doi.org/10.1088/1757-899X/596/1/012025

[12] D. S. Dharan , A. Lal, Study the effect of polypropylene fiber in concrete, Int. Res. J. Eng. Technol., 3 (2016) 618-619.

[13] N. Sohaib, F. Seem, G. Sana, R. Mamoon, Using polypropylene fibers in concrete to achieve maximum strength, Proc. of the Eighth International Conference on Advances in Civil and Structural Engineering CSE, Malaysia, 2018. https://doi.org/10.15224/ 978-1-63248-145-0-36

[14] M. Mastali ,A. Dalvand, Fresh and hardened properties of self-compacting concrete reinforced with hybrid recycled steel-polypropylene fiber, J. Mater. Civ. Eng., $29 \quad$ (2017) 2-13. https://doi.org/10.1061/(ASCE)MT.1943-5533.0001851

[15] Z. Marcalikova, L. Prochazka, M. Pesata, V. Bilek, R. Cajka, Mechanical properties of concrete with small fibre for numerical modeling, IOP Conf. Ser.: Mater. Sci. Eng., 596, 2019,012036. https://doi.org/10.1088/1757-899X/596/1/012036

[16] M. Chen, C. Ren, Y. Liu, Y. Yang, E. Wang ,X. Liang, Effects of polypropylene fiber and strain rate on dynamic compressive behavior of concrete, Materials, 12 (2019) 2-17. https://doi.org/10.3390/ma12111797

[17] M. V. Mohod, Performance of polypropylene fiber reinforced concrete, J. Mech. Civ. Eng., 12 (2015)2836. https://doi.org/10.9790/1684-12112836

[18] R. Othman, S. Khay, A. Loulizi , J. Neji, Laboratory evaluation of an ecological pavement construction material: sand concrete reinforced with polypropylene fibers, Eur. J. Environ. Civ. Eng., 23(2019)287-299. https://doi.org/10.1080/19648189.2016.1277372

[19] D. Wang, Y. Ju, H. Shen, L. Xu, Mechanical properties of high performance concrete reinforced with basalt fiber and polypropylene fiber, Constr. Build. Mater., 197(2019) 464-473. https://doi.org/10.1016/j.conbuildmat.2018.11.181

[20] L. Nevřivová, N. Žižková, The Influence of crystallization additives on the porosity of polypropylene fiber-reinforced cement mortar, IOP Conf. Ser.: Mater. Sci. Eng., 522.2019,012013. https://dx.doi.org/10.1088/1757-899X/522/1/012013 
[21] H. Sarikaya, G. Susurluk, Effect of polypropylene fiber addition on thermal and mechanical properties of concrete, . Res. Eng. Struct. Mat., 2 (2019)1-12. http://dx.doi.org/10.17515/resm2018.72ma1109

[22] W. Yao, J. Lib, K. Wua, Mechanical properties of hybrid fiber-reinforced concrete at low fiber volume fraction, Constr. Build. Mater., 33(2003)27-30. https://doi.org/10.1016/S0008-8846(02)00913-4

[23] Y. Chen, P. Qiao and F. Asce, Fracture of hybrid microfiber reinforced cement composites, The 11th ASCE Aerospace Division International Conference (Earth and Space 2008) Long Beach, CA, USA, 2008. https://doi.org/10.1061/40988(323)44

[24] M. Gesoğlu, E. Güneyisi, G. Muhyaddin, D. Asaad, M. Yılmaz, Strain hardening ultra-high performance fiber reinforced Cementitious Composites: Effect of fiber type and concentration, Compos. B. Eng., 103(2016) 74-83. https://doi.org/10.1016/j.compositesb.2016.08.004

[25] British Standards, Concrete, Methods for specifying concrete mixes, BS 5328-2, BSI Group, 1997.

[26] British Standards, Specification for aggregates from natural sources for concrete, BS 882, BSI Group, 1992.

[27] British Standards, Sulfate-resisting Portland cement, BS 4027, BSI Group, 1996.

[28] British Standards, Testing Concrete, Methods for determination of slump, BS 1881-102, BSI Group, 1983.

[29] British Standards, Testing Concrete, Method for determination of compressive strength of concrete cubes, BS 1881-116, BSI Group, 1983.

[30] American Society for Testing and Materials, Standard Test Method for Density, Absorption, and Voids in Hardened Concrete, Designation, ASTM C 642, 2006.

[31] British Standards, Testing Hardened Concrete, Flexural strength of test specimens, BS EN 12390-5, BSI Group, 2009.

[32] American Society for Testing and Materials, Standard Specification for Fiber-Reinforced Concrete, ASTM C1116, 2015.

[33] British Standards, Admixtures for concrete, mortar and grout, Concrete admixtures, Definitions, requirements, conformity, marking and labeling, BS EN 934-2, BSI Group, 2001.

[34] British Standards, Aggregates for concrete, BS EN 12620, BSI Group, 2013.

[35] British Standards, Testing Concrete, Method of Normal Curing of Test specimens $\left(20^{\circ} \mathrm{C}\right.$ method), BS 1881-111, BSI Group, 1983. 